\title{
O EQUILÍBRIO CONTRATUAL NO DIREITO PRIVADO PÓS-MODERNO: A (RE)SIGNIFICAÇÃO DA JUSTIÇA DO CONTRATO NO MICROSSISTEMA DE DEFESA DO CONSUMIDOR.
}

\author{
Priscila Borges da Silveira ${ }^{1}$ \\ Tatiana Bruhn Parmeggiani
}

\section{RESUMO}

Este estudo analisa o significado da justiça contratual sob o viés da teoria clássica contratual e o da teoria contratual renovada, pertencente ao microssistema de defesa do consumidor. Alterados os valores de cada tempo, a liberdade contratual e a igualdade formal tornaram-se relativizadas, dividindo espaço com a confiança e a boa-fé, de modo que a justiça contratual, naquele e neste contexto, não se reconhece como de idêntico conteúdo, tornando necessário, no direito do consumidor, a sua (re)significação, não individualizada e preenchida de interesses egoísticos, mas, sim, socializada, protegendo as legítimas expectativas dos consumidores.

PALAVRAS-CHAVE: Microssistema de Defesa do Consumidor; Proteção Contratual do Consumidor; Justiça Contratual; Direito ao Equilíbrio do Contrato; Confiança e Boa-fé.

\section{CONTRACTUAL EQUILIBRIO IN POSTMODERN PRIVATE LAW: THE RE-SIGNIFICATION OF CONTRACTUAL JUSTICE WITHIN THE MICROSYSTEM OF CONSUMER DEFENSE.}

\begin{abstract}
This study analyses the meaning of contractual justice based on the classical theory of contracts and the renewed contract theory, part of microsystem of consumer defense. As the values of each period have changed over time, the contractual freedom and formal equality started being relativized and dividing space with the good faith and trust. Contractual justices not recognized as having identical content on both contexts, and it's necessary to re-signify it within the consumer of law. It can no longer be individualized or filled with selfish interests, but it should be socialized to protect the legitimate expectations of the consumer.
\end{abstract}

KEYWORDS: Microsystem of Consumer Defense; Contractual Protection of Consumers; Contractual Justice; Right of Contractual Equilibrium; Good Faith and Trust.

1 Mestranda em Direito Privado, com ênfase em Direito do Consumidor, pela Universidade Federal do Rio Grande do Sul (UFRGS). Especialista em Processo Civil e em Direito do Consumidor pela Universidade Federal do Rio Grande do Sul (UFRGS). Graduada em Direito pela Fundação Escola Superior do Ministério Público do Rio Grande do Sul (FMP). Integrante do Grupo de Pesquisa "Direito Privado e Acesso ao Mercado", coord. pelo Prof. Dr. Bruno Miragem e vinculado ao CNPq, da Universidade Federal do Rio Grande do Sul. Bolsista com dedicação exclusiva pela Coordenação de Aperfeiçoamento de Pessoal de Nível Superior (CAPES). Advogada licenciada. E-mail: pborgesdasilveira@gmail.com.

2 Mestranda em Direito pela Universidade Federal do Rio Grande do Sul (UFRGS). Especialista em Direito Internacional Público e em Direito Internacional Privado pela Universidade Federal do Rio Grande do Sul (UFRGS). Graduada em Direito pela Pontifícia Universidade Católica do Rio Grande do Sul (PUC/RS). Integrante do Grupo de Pesquisa "Direito Internacional da Concorrência, coord. pelo Prof. Dr. Augusto Jaeger Júnior e vinculado ao CNPq, da Universidade Federal do Rio Grande do Sul (UFRGS). Bolsista com dedicação exclusiva pela Coordenação de Aperfeiçoamento de Pessoal de Nível Superior (CAPES). Advogada. E-mail: tatibruhn@hotmail.com. 


\section{INTRODUÇÃO}

No microssistema de defesa do consumidor brasileiro, pertencente à seara do Direito Privado Pós-Moderno, a justiça contratual tem, em seu núcleo, o equilíbrio contratual das relações de consumo. É sobre esse objeto que versa a presente pesquisa.

Diz-se que houve, no cenário da sociedade de consumo, uma (re)significação do conteúdo (do princípio) da justiça contratual, na medida em que esta não tem, em nada, a ver com aquela chamada "justiça contratual" enunciada pelo (e para o) Direito Privado Moderno. Assentada sobre os dogmas da liberdade contratual e da igualdade jurídica ou formal, justo eram os contratos formalizados por indivíduos livres e iguais. Assim, a justiça coincidiria com o preenchimento dos seguintes pressupostos: a um, a vontade dos contraentes ser livres de vícios; e, a dois, os contraentes serem dotados de capacidade.

Observa-se, nesse sentido, que o "equilíbrio" da relação contratual apenas poderia ser discutido, nessa realidade, em prol da realização econômica das atividades negociais e da prosperidade do sistema do liberalismo econômico - considerações, essas, que tangenciavam com o conteúdo propriamente dito do contrato. Uma vez realizada a respectiva celebração, não haveria mais a oportunidade de modificação de seu conteúdo - a não importar a razão. É claro que, principalmente após as Grandes Guerras, flexibilizou-se esse dogma do pacta sunt servanda, com institutos da teoria da imprevisão e da lesão, por exemplo, mas fato é que não se discutia, sequer minimamente, sobre o conteúdo dos contratos (isto é, sobre os direitos e os deveres de cada contraente) e sobre a necessidade de se agir em face de desigualdades reais e concretas de seus participantes. Importava, pois, conservar a abstratividade do instituto, pois esta é a que permitia a liberdade necessária ao desenvolvimento socioeconômico almejado pela classe influente do período, a burguesia.

Com as alterações desencadeadas pela Revolução Social nas sociedades ocidentais, a teoria clássica contratual resultou fortemente atingida. Os seus pilares fundamentais, formados pelos valores da liberdade econômica, do patrimônio e do voluntarismo contratual, não mais tinham efeito satisfatório no ambiente em que inseridos. Ademais, em razão dos danos provocados na Era do Maquinismo, os indivíduos passaram a requerer providências sociais do Estado. O interesse social tornou-se relevante no contexto que ascendia. O que se 


\section{O EQUILÍBRIO CONTRATUAL NO DIREITO PRIVADO PÓS-MODERNO: \\ A (RE)SIGNIFICAÇÃO DA JUSTIÇA DO CONTRATO NO MICROSSISTEMA DE DEFESA DO \\ CONSUMIDOR}

compreendia por justo na teoria contratual clássica pertencente ao Direito Privado Moderno não mais se poderia compreender, especialmente no tocante ao mercado de consumo.

As premissas da teoria contratual alteraram-se por completo, de modo que, no Microssistema de Defesa do Consumidor, pode-se dizer que houve uma profunda renovação de seus valores e, pois, de seu conteúdo - assim, da estrutura e da função. A restrição da liberdade contratual e valorização da igualdade em sua face substancial não mais poderiam conceber o justo contratual como aquele que foi celebrado por agentes capazes e com vontades livres.

As forças do contrato desequilibraram-se por natureza: de um lado, o fornecedor, agente econômico da relação, conhecedor e detentor do objeto de consumo, e, de outro lado, o consumidor, pessoa física, inequivocamente mais fraco em relação àquele - é aqui que nasce a sua vulnerabilidade (econômica, técnica, informacional etc.). A partir dessa realidade, consideravelmente diversa da anterior, buscou, o microssistema, (re)significar o instituto do contrato e a sua teoria, de modo a buscar promover a proteção efetiva dos consumidores no mercado de consumo, uma vez que não há mais de se presumir, na celebração dos contratos, a liberdade; assim, não há de se presumir o justo nesse sentido.

Uma vez expostas as noções introdutórias da presente pesquisa, passa-se, brevemente, a delinear a sua estrutura: na primeira parte, dedica-se a uma análise socioeconômica sobre a justiça do contrato no Direito Privado Moderno. Em suas duas subdivisões serão abordados os dogmas da teoria clássica contratual, quais sejam, o da liberdade e o da igualdade formal, e o significado da justiça contratual naquele contexto, tornando relevante a consideração de que o conteúdo deste último foi permeado por perspectivas ideológicas do período.

Na segunda parte, será examinada a modificação da identidade da justiça contratual quando inserida no Microssistema de Defesa do Consumidor. Assim, será examinado o equilíbrio da relação contratual de consumo, o qual nasceu da renovada visão da teoria dos contratos neste ambiente real (mercado de consumo) e jurídico (Microssistema de Defesa do Consumidor); e, em seguida, a compor o conteúdo da (re)significação da justiça contratual no Microssistema de Defesa do Consumidor, examinar-se-ão dois de seus pilares, de um lado vocacionados a equilibrar o contrato e, de outro, a limitar a liberdade contratual anteriormente dogma do instituto: é o princípio da confiança e o principio da boa-fé. 
Esta pesquisa, do tipo bibliográfica, adotou a seguinte metodologia jurídica: como método de abordagem, o dedutivo, na medida em que as suas conclusões partem da construção de suas premissas, através de um encadeamento lógico de construção das ideias; e, como método de procedimento, especialmente, utilizou o histórico, quando da análise da evolução do tema a partir de seu viés socioeconômico da modernidade e, posteriormente, da pós-modernidade, revelando as identidades da justiça contratual a partir de seus vieses historicamente situados.

\section{UMA BREVE ANÁLISE SOCIOECONÔMICA SOBRE A JUSTIÇA CONTRATUAL NO DIREITO PRIVADO MODERNO}

\subsection{OS DOGMAS DA LIBERDADE CONTRATUAL E DA IGUALDADE FORMAL COMO CERNES DA TEORIA CLÁSSICA}

Para que se possa compreender o significado da justiça contratual no contexto do Direito Privado Moderno, necessário será, de antemão, analisar o cenário socioeconômico que o envolve, e, fundamentalmente, os dogmas da teoria clássica, pois estes edificam todo o respectivo conteúdo, indicando o caminho que aquela teoria visou percorrer por meio do instrumento contratual (MARQUES; MIRAGEM, 2012).

A Modernidade teve, como termo inicial, a Revolução Francesa, datada de 1789, a qual, acompanhada da Declaração de Direitos do Homem e do Cidadão, de mesmo ano, marcaram o fim do Antigo Regime, este constituído por uma Monarquia Absoluta (BOBBIO, 2004; REALE, 1990). Até então, a sociedade francesa tinha o seu poder centralizado na figura do rei e era composta, para além dele, por três estamentos - o clero, a nobreza e o terceiro estado (de um lado, a burguesia, esta formada pelos comerciantes de todos os ramos, os profissionais liberais e os proprietários urbanos e, de outro lado, pelo resto do povo, em critério de exclusão; a saber, os não-proprietários, os pequenos artesãos e os camponeses) (COMPARATO, 2015).

No referido contexto social da Idade Média, em flagrante tirania, o rei concedia privilégios feudais à aristocracia (o clero e a nobreza, portanto), em detrimento do Terceiro Estado - de um lado, restringia a liberdade econômica dos burgueses, e, de outro lado, oprimia o povo (COMPARATO, 2015). Assim, a Revolução serviu como uma luta de 


\section{O EQUILÍBRIO CONTRATUAL NO DIREITO PRIVADO PÓS-MODERNO: \\ A (RE)SIGNIFICAÇÃO DA JUSTIÇA DO CONTRATO NO MICROSSISTEMA DE DEFESA DO \\ CONSUMIDOR}

emancipação da burguesia em face da aristocracia, premissa, essa, que pode ser confirmada pelo teor da Declaração de Direitos do Homem e do Cidadão, a qual atendeu aos anseios daquela: enunciou a proteção da propriedade privada contra expropriações de natureza abusiva e a necessidade de estrita legalidade para a criação e para a cobrança de tributos (BOBBIO, 2004; COMPARATO, 2015). Em síntese, a Revolução aboliu a dominação social fundada na propriedade, assim como fez desaparecer a divisão dos indivíduos por estamentos e as corporações (COMPARATO, 2015).

O Estado Moderno, em contraposição ao período que lhe antecedeu, acima brevemente delineado, instituiu-se sob as vestes de um Estado de abstenção, não-interventor e liberal (COUTO E SILVA, 2006). Os paradigmas da nova ordem social que ora se estabelecia foram os da liberdade, da igualdade e da fraternidade, e, o seu valor nuclear, o do individualismo (REALE, 1990). A concepção individualista fez surgir a premissa maior de que o homem, singular e abstratamente considerado, tinha valor em si mesmo, e, por isso, deveria ser tratado de modo a poder realizar a satisfação de seus interesses e de seus fins próprios e egoísticos (BOBBIO, 2004).

Ao Estado, este, sob o presente viés, edificado pelos homens, incumbiria o dever de firmar um espaço em que os direitos de liberdade dos indivíduos (negativos ao Estado, portanto) pudessem ser exercidos. Para essa concepção, pois, o indivíduo haveria de ser considerado independentemente dos outros, a fim de que lhe fosse permitido perseguir as suas próprias felicidades (BOBBIO, 2004). A referida percepção de valorização do homem e incentivo a que fosse ampliado o seu espaço de liberdade de atuação na sociedade, para a persecução de seus próprios interesses, desencadeou na ascensão, nesse contexto, da autonomia privada (ANTUNES VARELA, 1998).

É necessário registrar, aqui, que o Direito Público e o Direito Privado, neste momento, considerados eram de territórios autônomos, estanques, sem qualquer interpenetração, a espelhar a separação entre o Estado e a sociedade (COUTO E SILVA, 2006). Ao Direito Público, pertencente ao Estado, incumbiu-se da competência para a sua organização, bem como de suas relações jurídicas; e, ao Direito Privado, através da autonomia privada e dos paradigmas do Estado Moderno (a liberdade e a igualdade, sobremaneira), a regulação da vida privada, da vida dos indivíduos, portanto (MARQUES; MIRAGEM, 2012).

A característica da centralidade do indivíduo para o Estado Moderno - a consubstanciar o individualismo puro, afastando o homem de uma vinculação histórica e, 
mesmo, de uma vinculação ao poder soberano, que tinham o condão de predestiná-lo, mas, sim, considerá-lo a partir de um conceito metafísico - provocou a redução deste a "ser", resultando na premissa de que "todos são iguais" (NEGREIROS, 2006). Trata-se, essa concepção, da enunciação de um outro paradigma de matriz liberal: o da igualdade formal, o da igualdade jurídica, a igualdade de todos os homens perante a lei (MARQUES, 2002).

Àquele tempo, não há de se desconsiderar a importância de uma visão formal e jurídica sobre o dogma da igualdade: na ordem previamente estabelecida, a do Antigo Regime, sem a liberdade exerciam-se, flagrantemente, desigualdades e privilégios (ROPPO, 2009). Em uma sociedade que adota o valor da igualdade jurídica ou formal, todos se tornam, ainda que abstratamente, iguais perante a lei, sem distinção de qualquer natureza, não se podendo conceber privilégios institucionais.

O Código Civil de Napoleão, de 1804, considerado a primeira grande Codificação da Modernidade, representou o coração da vida jurídica privada do contexto que ora se está a analisar (COUTO E SILVA, 2006). Este veio a ser concebido para unificar os direitos locais, bem como os costumes, no tráfico jurídico desenvolvidos, pois, ante a sua fragmentariedade, não conferiam previsibilidade e segurança à atuação negocial dos indivíduos (leia-se, da burguesia), assim travando os seus desenvolvimentos econômicos (ROPPO, 2009). Com base nessa orientação político-ideológica, pois, firmou-se que, em sendo todos os indivíduos iguais, tanto em direitos quanto em obrigações, deveriam, eles, ser submetidos ao mesmo Direito (MARQUES; MIRAGEM, 2012).

No que diz respeito à teoria clássica contratual da Modernidade, esta encontra o seu cerne no Code Civil, preenchida, em absoluto, pelo valor do individualismo (REALE, 1990). Este, nesse sentido, concebia que os indivíduos daquela sociedade haveriam de ser considerados, em regra, homens livres e aptos a celebrarem - pelo contrato - relações negociais, constituindo, modificando e extinguindo direitos, sem qualquer limitação às suas atuações, senão para garantir a realização dos efeitos da relação negocial pactuada (MARQUES, 2016). Vigia, então, o individualismo puro, sem qualquer resquício, em seu conteúdo, de uma função social, de consideração, ainda que mínima, ao alter (COUTO E SILVA, 2006).

O Código protegia e influenciava, sim, que os indivíduos perseguissem os seus próprios interesses de forma egoística, como se isolados estivessem (RIPERT, 2000). Cumpre registrar, nessa esteira, então, que se desconsideravam por completo as condições sociais e 


\section{O EQUILÍBRIO CONTRATUAL NO DIREITO PRIVADO PÓS-MODERNO: \\ A (RE)SIGNIFICAÇÃO DA JUSTIÇA DO CONTRATO NO MICROSSISTEMA DE DEFESA DO \\ CONSUMIDOR}

econômicas das partes, e mais ainda as razões que as levaram a contratar, as suas expectativas - estas, para a teoria clássica contratual, restavam como conjunto de questões indiferentes à tutela jurídica (MARQUES, 2016).

Premissa do individualismo, na teoria contratual, não há de ser outra senão a liberdade contratual dos indivíduos (ANTUNES VARELA, 1998; ROPPO, 2009). No exercício de suas relações contratuais, pressupõe-se (isso porque deverá existir, ao menos, abstratamente) que os indivíduos serão livres para decidirem sobre contratar ou não; também, sobre o tipo contratual a celebrar, podendo ser tipificados na lei ou não; e, ainda, e fundamentalmente, necessitam ser livres para estipularem o conteúdo do contrato, as suas cláusulas, os seus direitos e as suas obrigações (ALMEIDA COSTA, 2011; ANTUNES VARELA, 1998; LARENZ, 1959). Observa-se, assim, que a liberdade contratual, dogma fundamental da teoria clássica, analiticamente desenvolvido, abrange três aspectos que, se na prática conformados, demonstram-se, de forma plena, exercido (ALMEIDA COSTA, 2011).

Núcleo da liberdade contratual, e imprescindível ao seu exercício, era o dogma da autonomia da vontade, esta tão importante porque apta a conferir não só validade ao contrato, mas, também, legitimação (GOMES, 1967; MARQUES, 2016). A liberdade promovia espaço, então, para que os indivíduos agissem conforme as suas vontades, e essas ganhavam respaldo tão grande que - se livres e sem vícios - adquiriam força de lei e haveriam de ser cumpridas independentemente de qualquer circunstância, independentemente de qualquer condição social e/ou econômica das partes (COUTO E SILVA, 2006). Assim, não havia espaço, nesse contexto, para falar-se em justiça material ou substancial (ROPPO, 2009).

Compreendia-se que o elemento da vontade no contrato teria o condão de realizar o equilíbrio econômico e a prosperidade (NEGREIROS, 2006). Assim, em reconhecidas expressões remetidas a Fouilée, "toda a justiça é contratual", assim como "quem diz contratual, diz justo" (RIPERT, 2000).

Cumpre registrar, ainda, que pressuposto da liberdade contratual é a igualdade, segundo valor consagrado pela Revolução Francesa e considerado, pois, um dos grandes pilares da Modernidade e de seu Direito Privado, como anteriormente delineado (ANTUNES VARELA, 1998). Como já desenvolvido, há só de se fazer constar, aqui, que essa igualdade é a igualdade formal, que concebe a noção de todos os homens são iguais perante a lei.

A concepção clássica dos contratos, com os seus dogmas edificantes, influenciou a elaboração do Código Civil brasileiro de 1916, com a crítica de isso ter ocorrido quando, na 
verdade, já ultrapassado estava. Enquanto a sociedade industrializava-se, a adquirir novos valores e a sentir a necessidade de relativizar os seus dogmas clássicos, para que com ele surgissem outros - como a boa-fé, por exemplo - o Código refletia uma sociedade já não mais existente, de características rural e conservadora (MARQUES; MIRAGEM, 2012).

\subsection{A JUSTIÇA CONTRATUAL COMO MANTO DE CONCRETIZAÇÃO DOS IDEAIS BURGUESES}

Há de se observar, aqui, a ausência de importância ao equilíbrio da relação contratual no modelo da teoria clássica. A justificativa, para tanto, é multifatorial: a um, pode-se, assim, compreender, porque o foco da teoria contratual encontrava-se no elemento da vontade dos contraentes (ANTUNES VARELA, 1998; MARQUES, 2016); a dois, assim se pode concluir na medida em que, mesmo que pudesse resultar em prejuízo aos contraentes, o contrato haveria de ser cumprido tal como a manifestação inicial de vontades em acordo (RIPERT, 2000). Também, porque os dogmas firmados na teoria clássica consubstanciavam a figura de um homem livre e abstrato, demonstrando conceitualismo puro em sua composição, impedindo a conversão de uma análise distante e superficial para a do caso concreto, em análise ao conteúdo da relação contratual, de modo a substancialmente verificar a existência de desequilíbrios reais.

Para a teoria clássica contratual, pois, a justiça do contrato nascia quando dois indivíduos livres e iguais, através da manifestação de suas vontades, decidiam celebrar determinado contrato, exercendo os seus direitos de estipularem o respectivo conteúdo sem qualquer limitação do Estado. Nesse ambiente, "parecia que todos os contratantes conscientes e capazes saberiam bem defender-se a si próprios" (RIPERT, 2000, p. 111). Apenas preocupavam-se, os operadores daquele Direito, para que o seu conteúdo fosse cumprido tal como estabelecido pelas partes.

A história revela que a Revolução Francesa foi evento que ocorreu por forte influência de uma burguesia que ascendia no contexto social da Idade Média e que precisava, para o desenvolvimento de suas atividades negociais, de um ambiente, em muito, diferente daquele que antecedeu a Revolução (ROPPO, 2009). Os tributos eram excessivos ao Terceiro Estado, as regras sobre o comércio eram fragmentadas e locais, havia privilégios feudais ao clero e à nobreza. Os burgueses necessitavam, assim, de liberdade para a realização de seus 


\section{O EQUILÍBRIO CONTRATUAL NO DIREITO PRIVADO PÓS-MODERNO: \\ A (RE)SIGNIFICAÇÃO DA JUSTIÇA DO CONTRATO NO MICROSSISTEMA DE DEFESA DO \\ CONSUMIDOR}

negócios, sem limitações ao respectivo exercício por meio de regras locais e costumeiras; e, precisavam, também, de uma igualdade que abolisse os privilégios feudais herdados outrora (COMPARATO, 2015; ROPPO, 2009).

A possibilidade de uma unificação na legislação vigente, para, de um lado, resolver o problema de sua fragmentação e, de outro, a aumentar a previsibilidade e a segurança das relações negociais, haveria, em muito, de contribuir para o aprimoramento das atividades da burguesia. Observa-se, do exposto, que a Revolução Francesa viera a enunciar a nova ordem valores que, sem dúvidas, beneficiariam e alavancariam sobremaneira os interesses dessa categoria burguesa.

Os contratos, aqui, hão de representar, na realidade aludida, mais do que uma categoria do Direito Privado, mas verdadeira pedra angular daquele Direito (ALMEIDA COSTA, 2011; MARQUES, 2016). A bem da verdade, a teoria clássica contratual revela, de seu conteúdo, o espelho daquela sociedade pós-revolucionária, guiada pelo valor de um individualismo puro, premissa necessária à edificação de dogmas absolutos como o da liberdade contratual e o da igualdade formal (ALMEIDA COSTA, 2011).

Não há de se perder, nesse sentido, a compreensão de que por trás de toda a teoria clássica e secular dos contratos na Modernidade há uma ideologia a falsificar a aparente realidade, e que, no fundo, possuía intenção outra que não aquela transparecida: a liberdade, a igualdade e a fraternidade que impulsionaram a mudança não foi concebida para proporcionar uma melhora àqueles que restavam marginalizados no Antigo Regime, mas, sim, tratava-se de uma liberdade, de uma igualdade e de uma fraternidade - como até agora exposto - à burguesia, especificamente para possibilitar o avanço de suas atividades negociais (COMPARATO, 2015; ROPPO, 2009). Por atividades negociais, chamou-se a instrumentalizar essas operações, o contrato, que, por sua vez, a repetir brevemente, acaba por abarcar em sua teoria os valores socioeconômicos do período, e a beneficiar, tal como estes, a própria burguesia (ROPPO, 2009).

Pelo que foi exposto até agora, torna lógico concluir que a justiça contratual, naquele período, não haveria de ser a justiça de todo e qualquer contratante, em suas vidas reais considerados, mas, sim, a justiça do contrato que viria a permitir o desenvolvimento e o aprimoramento dos comerciantes burgueses (ROPPO, 2009). Estes tinham o objetivo de perseguir os seus interesses econômicos sem ter de encontrar entraves, isto é, inseguranças, em questões como a fragilidade da parte contrária com quem negociavam, nem com questões 
futuras que viessem a corromper as circunstâncias que fizeram os negócios acontecerem. A justiça contratual dar-se-ia, assim, em um pedestal, distante da realidade, quando o conteúdo do contrato fosse cumprido tal como a vontade inicial dos contraentes houvesse firmado.

Não há espaço, nem demonstra-se pertinente, aqui, cogitar trabalhar com conceitos como equilíbrio contratual, pois a avaliação sobre as prestações e as contraprestações das partes - e os seus respectivos equilíbrios ou desequilíbrios - tratavam-se de questões indiferentes à teoria, a qual focava, repita-se, na vontade das partes no ato da celebração e da estipulação do conteúdo. A justiça atingia o seu êxtase ali.

Assim, falar-se em justiça contratual na teoria clássica dos contratos, pertencente ao Direito Privado Moderno, é não a utilizar em uma compreensão global de todos os vieses da categoria do contrato, como sendo verdadeiramente um de seus fundamentos, mas, sim, a de minimizá-la a ponto de poder situá-la tão somente na conformação da justiça contratual da parte contraente beneficiada com um negócio econômico, e tão-só. Venda-se os olhos da justiça para todo o mais, tornando-se indiferente sobre mesmo a possibilidade de uma desigualdade material, substancial, real.

O Estado Liberal e a teoria clássica dos contratos, com os seus valores do individualismo, do liberalismo e do patrimonialismo proporcionaram o avanço econômico daquela sociedade de escassez, até então consubstanciada por relações contratuais paritárias ou individuais, personalizadas e artesanais. Consequência da referida evolução foi a eclosão da Revolução Industrial, fenômeno que modificou mais do que a economia, mas a própria forma de vida dos indivíduos, daquele período em diante.

Importa considerar, assim, que no cenário que se modificava com acentuada rapidez, ruíam os valores da sociedade moderna, como o do individualismo puro, bem como a teoria clássica e os seus dogmas norteadores, na medida em que a liberdade contratual não se demonstrava vivenciada pela prática dos contratos pós-revolução industrial, bem como não havia mais de se dizer que a igualdade entre as partes eram evidentes - pelo contrário: era flagrante a diferença entre os contraentes, de modo que um adquiria contornos empresariais, enquanto o outro não passava de um cliente a adquirir um produto em série.

No tocante à justiça contratual situada nesse contexto histórico de transformação, há de se fazer uma consideração. Como acima afirmado, a justiça contratual para a teoria clássica, era a justiça que selecionava os interesses dos comerciantes burgueses; a justiça era aquela que viria a promover a sua aquisição econômica pelos tráficos comerciais. 


\section{O EQUILÍBRIO CONTRATUAL NO DIREITO PRIVADO PÓS-MODERNO: \\ A (RE)SIGNIFICAÇÃO DA JUSTIÇA DO CONTRATO NO MICROSSISTEMA DE DEFESA DO}

CONSUMIDOR

Não apenas o dogma da liberdade contratual perdia a sua força, mas a igualdade formal demonstrava-se insuficiente a atender os reclames da sociedade. Se antes bastava a sua face jurídica, porque as relações, em essência, se não formada por indivíduos iguais, ao menos o fazia em condições semelhantes (entre duas pessoas físicas, a exemplo), na nova realidade não mais se sustentava. Isso porque as relações estabelecidas entre os empresários e os seus clientes, em contratos de compra e venda de bens de consumo, não mais era estabelecida entre dois agentes iguais - mas um, pessoa física, e outro empresário, caracterizando-se como um profissional ou uma teia de profissionais experientes a realizar a operação econômica de um bem que produz e que, pois, tem domínio técnico e informacional sobre o seu conteúdo.

A considerar, ademais, que, para além da despersonalização dessas relações, por um quesito de racionalização da atividade econômica, a interessar a todos pelos benefícios sociais que representam, como demonstra o avanço da sociedade como um todo, permitiu-se a ausência de igualdade entre as partes no tocante às suas liberdades contratuais. Rompeu-se a liberdade, pois, no momento da celebração do contrato - especialmente, quanto à estipulação dos termos contratuais - fazendo surgir, como característica comum a relações negociais no contexto em análise, um desequilíbrio nesse momento estrutural.

A desigualdade recém-enunciada serviu de alerta a demonstrar, aos juristas daquele período, que o dogma da igualdade formal não mais se encaixava à sociedade como se considerava - o conteúdo dele não era absoluto, total, perfeito e válido em todos os tempos como tinha a intenção de ser. As desigualdades fáticas que surgiam a cada dia dessas novas relações que se estabeleciam demonstravam que seria necessário uma nova resposta do Direito, pois as injustiças passavam a se tornar visíveis e não mais indiferentes como outrora.

\section{A JUSTIÇA CONTRATUAL NO DIREITO PRIVADO PÓS-MODERNO: A CONTRIBUIÇÃO DO MICROSSISTEMA DE DEFESA DO CONSUMIDOR}

2.1 A RENOVADA TEORIA CONTRATUAL E SUA MATRIZ PRINCIPIOLÓGICA: A CONSTRUÇÃo do EQUiLíbrio CONTRATUAL NAS RELAÇÕES DE CONSUMO 
Tem-se que o século XIX, predominantemente, representou um período de tranquilidade, com quadros econômicos dotados de estabilidade. Na ciência do Direito, igualmente, não houve turbações consideráveis, uma vez que predominavam os vieses dogmáticos da Escola da Exegese, a simplificar a aplicação do Direito aos textos da lei, através do método subsuntivo (PEREIRA, 1994).

Com o desenvolvimento e evolução do capitalismo, a partir do século $\mathrm{XX}$, e o progresso da máquina, observou-se o crescimento dos poderes econômicos dos grupos, de maneira a alterar consideravelmente as atividades das empresas (ANTUNES VARELA, 1998). Estas não só passaram a produzir e a distribuir em quantidades elevadas, mas, também, diversificaram sobremaneira os seus bens ofertados. Assim, pode-se dizer que a Revolução Industrial provocou um "extraordinário aumento de atos jurídicos” (MENEZES CORDEIRO, 1994, p. 97).

Em contrapartida, crescia, também, a massa de clientes (ainda não chamados, a esse tempo, de "consumidores") a conviver no novo mercado e a consumir os bens, então, lá produzidos e comercializados (REALE, 1990). Sob essa ótica, própria de uma Era capitalista, ocorria a "progressiva conversão do proletário em fruidor da classe média" (REALE, 1990). Compreendia-se, no referido contexto, a partir de uma visão liberal-econômica, que os clientes tinham, no mercado de consumo, os seus desejos realizados, na medida em que eram considerados os "reis" daquele ambiente, pois detentores de liberdade e do poder de suas vontades (BENJAMIN; MARQUES; BESSA, 2014).

Para as teorias econômicas da época (do laissez-faire, laissez-passer), o bem-estar da coletividade apenas poderia ser alcançado com eficiência se não houvesse intervenções do Estado. O raciocínio era o de que os próprios mecanismos do mercado e da concorrência automaticamente conduziriam a uma maior otimização dos recursos (ROPPO, 2009).

No desenvolvimento do cenário do mercado de consumo anteriormente ilustrado, surgiram instrumentos contratuais elaborados, de forma prévia e unilateral, pelas empresas, a serem ofertados, de forma genérica, a um número indefinido de clientes (ANTUNES VARELA, 1998; COUTO E SILVA, 2006; LARENZ, 1959). Esses contratos tinham (e têm), como elementos essenciais, a generalidade e a rigidez - a generalidade porque não é, tal como no período anterior, dirigido a uma pessoa específica, mas, sim, a todos aqueles que se inserem no mercado de consumo; e, rigidez porque só podem ser recebidos em bloco pela 


\section{O EQUILÍBRIO CONTRATUAL NO DIREITO PRIVADO PÓS-MODERNO: \\ A (RE)SIGNIFICAÇÃO DA JUSTIÇA DO CONTRATO NO MICROSSISTEMA DE DEFESA DO \\ CONSUMIDOR}

outra parte, a qual não tem liberdade de modelar o conteúdo do contrato (MENEZES CORDEIRO, 1994).

A implementação da referida forma de contratação no ascendente mercado de consumo possibilitou, aos fornecedores em geral, a racionalização da atividade econômica e de consumo, fornecendo rapidez, segurança e previsibilidade de riscos (MARQUES, 2016). Permitiu, assim, o cálculo antecipado dos elementos suscetíveis de serem quantificados como ativos e como passivos no balanço empresarial. Logo, não se tratava de um "jogo puro e simples de interesses privados", mas, sim, de "uma necessidade fundamental da organização de um serviço" (RIPERT, 2000, p. 115).

Se se compreende que a liberdade contratual é preenchida pela liberdade que tem, o contraente, de decidir livremente sobre celebrar, ou não, determinada relação contratual, e com a liberdade de configuração interna acerca do respectivo conteúdo, então pode-se concluir, como lógico, que há considerável restrição na liberdade contratual dos clientes no tocante a essas contratações no mercado de consumo (ALMEIDA COSTA, 2011; LARENZ, 1959;). É essencial, aqui, compreender que as contratações em massa suprimiram "a fase prénegocial decisiva" entre os contratantes, desencadeando a "falta de um debate prévio das cláusulas contratuais" e, pois, resultando na perenização de uma "assimetria de forças" que impede "uma verdadeira comunicação entre os futuros parceiros" (MARQUES, 2016, p. 7879).

É imprescindível reconhecer, até aqui, que a limitação contratual provocada pelos contratos de massa apenas o são no que diz respeito ao "domínio dos fatos", pois - na lei vigente àquele período - não havia qualquer menção a respeito dessa limitação (VARELA, 1998). Ao contrário, enunciavam-se os valores do liberalismo econômico, da igualdade formal, do voluntarismo jurídico, sendo, os contraentes, livres a celebrarem os contratos tal qual as suas vontades. Verdade é que, neste ponto, latente ficou a desigualdade material dos casos concretos que se vivenciava nesse novo mercado.

Seria preciso, assim, buscar-se uma resposta para conciliar, de um lado, o legítimo interesse econômico das empresas em utilizar contratos de adesão em suas programações contratuais, pelas razões anteriormente enumeradas, e, de outro lado, assegurar a proteção jurídica daqueles clientes que se tornavam frágeis naquele ambiente que visa, a qualquer custo, o lucro (ANTUNES VARELA, 1998; COUTO E SILVA, 2006). A bússola jurídica, como ensina o Mestre Caio Mário, apontou, então, para um novo norte "e então surgiu uma 
construção espiritualizante que visa à justiça no contrato baseada nas razões de humanidade" (PEREIRA, 1994, p. 156).

Ante as desigualdades fáticas, e no contexto pós-industrial, emergiram, no seio social, anseios por justiça no tocante ao mercado de consumo; a resposta do Direito foi a criação de normas jurídicas imperativas de proteção às pessoas consideradas frágeis naquele ambiente - foram promulgadas, então, normas jurídicas de compensação da desigualdade real (NEGREIROS, 2006). Mais do que isso, a ciência jurídica, do século XX em diante, fundamentalmente, passou a ser orientada por princípios sociais, de modo a atuar no sentido de promoção de interesses coletivos, de harmonia social, em evidente contramão ao individualismo puro de outrora.

Assim, "corrige situações injustas a que conduziu, quando imperava na órbita política e econômica do liberalismo, dando-lhes conteúdo mais humano, social e ético" (GOMES, 1967, p. 01-02). A trilhar esse caminho, o Direito Privado não mais poderia fechar os olhos para a tutela dos grupos que se revelaram mais frágeis - o consumidor, o trabalhador, a criança e o adolescente, a pessoa idosa, os índios etc. Inicialmente iluminado pela função social, o Direito Privado afastou-se do individualismo puro, a ponto de que, hoje, tornou-se solidário - tem, em seu vértice, como guia, a proteção da pessoa humana (MARQUES; MIRAGEM, 2012).

Com a promulgação da Constituição Federal de 1988, no Brasil, e, em seguida, do Código de Defesa do Consumidor em 1991, e, pois, a edificação de seu microssistema, o contrato tornou-se um importante marco de 'mudança de mentalidade', visando, a sua teoria renovada, alcançar, de um lado, o equilíbrio da relação contratual, com a proteção do consumidor, e, de outro lado, a justiça contratual, apenas alcançável quando possível e atingida a anterior (NEGREIROS, 2006).

O consumidor e o fornecedor celebram contrato de consumo com a intenção de realizarem uma troca recíproca e segura de prestações e de contraprestações. Há, no cerne dessa relação, a necessidade de se encontrar um equilíbrio mínimo entre os compromissos assumidos por cada um (isto é, um equilíbrio mínimo entre os direitos e os deveres de cada parte), o qual permita, por meio de uma visão global da relação de consumo, alcançar os objetivos almejados por cada parte quando da celebração desse instrumento contratual (MARQUES, 2016). 


\section{O EQUILÍBRIO CONTRATUAL NO DIREITO PRIVADO PÓS-MODERNO: A (RE)SIGNIFICAÇÃO DA JUSTIÇA DO CONTRATO NO MICROSSISTEMA DE DEFESA DO

Observa-se que não é a vulnerabilidade (em suas diversas e possíveis vertentes, a depender do caso concreto) do consumidor perante o seu fornecedor que tornará, por si só, o contrato injusto; sabe-se, nesse sentido, que essa desigualdade existe e é até mesmo presumida, com raras exceções. O que torna, sim, prejudicial e injusto o seu conteúdo é, da desigualdade real, partirem-se abusos, como aquele que resulta da exploração de "um contratante pelo outro" (MARQUES, 2016, p. 58).

Não há de se admitir, assim, o mau uso da liberdade dos fornecedores, para que seus consumidores não sejam onerados em excesso (MIRAGEM, 2017). No teor do artigo $4^{\circ}$ do Código de Defesa do Consumidor, o legislador enunciou o princípio do equilíbrio das relações de consumo. Em seguida, no artigo $6^{\circ}$, tratou o equilíbrio contratual como direito subjetivo do consumidor (MIRAGEM, 2016). Este, em suma, representa o que até aqui foi exposto. A justiça contratual, sob esta visão do microssistema, há de ser aquela que alcança o equilíbrio das relações de consumo em três sentidos fundamentais: no conteúdo econômico do contrato; no conteúdo informacional fornecido por uma parte a outra; e no que diz respeito ao poder de direção da relação contratual (MIRAGEM, 2016).

\subsection{A (RE)SIGNIFICAÇÃO DA JUSTIÇA CONTRATUAL SOBRE OS PILARES DA CONFIANÇA E DA BOA-FÉ}

Na contemporaneidade, não há como se conceber uma ideia de justiça contratual a partir, tão-só, da igualdade sob a veste formal, jurídica, em que todos são iguais perante a lei. É preciso compreender, pois, que, no conteúdo da (re)significação da justiça contratual no microssistema de defesa do consumidor, esta tem, como ponto de partida, a proteção dos consumidores no mercado de consumo, uma vez que a pessoa humana tornou-se o valor ápice do sistema. Estes sujeitos de direito precisam ser enxergados em suas particularidades e diferenças (MARQUES; MIRAGEM, 2012).

Por óbvio, não foram suprimidos os dogmas da teoria clássica na realidade presente, quais sejam, o da liberdade contratual e o da igualdade formal, mas, sim, estes - de absolutos -, foram relativizados, de modo a conviverem com princípios, outros, próprios de um tempo contemporâneo e pós-moderno (BENJAMIN; MARQUES; BESSA, 2014). É o caso, aqui, do equilíbrio, da boa-fé e da confiança. 
Assim, a liberdade contratual transformou-se, de antigo dogma, a princípio na matriz principiológica do microssistema de defesa do consumidor, como preceituam o artigo 170 da Constituição Federal e o artigo $4^{\circ}$ do Código de Defesa do Consumidor. Porém, essa liberdade - na medida em que é maior para os fornecedores do que para os consumidores - foi limitada, essencialmente, pela confiança e pela boa-fé, valores, outros, de semelhante hierarquia, emanados pelo microssistema. Tratam-se, estes, da "salvaguardia que forman la base del tráfico jurídico" (LARENZ, 1959), a não permitir que a saudável liberdade, inerente e estimulada no contrato, em razão do poder dos fornecedores, transforme-se em abusividade; em desvantagem exagerada ao sujeito vulnerável consumidor (BENJAMIN; MARQUES; BESSA, 2014).

Compreende-se o ato de confiar a partir de três perspectivas, como ensina o Mestre português Carneiro da Frada: confia quem "crê firmemente em uma certa realidade"; quem "espera com uma convicção mais moderada"; e, quem "chega a adotar determinado comportamento apesar de uma contingência que não domina, decidido a assumir o correspondente risco na expectativa de que ele não se concretize" (CARNEIRO DA FRADA, 2004, p. 17-18). A complementar, Menezes Cordeiro afirma que "a confiança exprime situação em que uma pessoa adere, em termos de atividade ou crença, a certas representações, passadas, presentes ou futuras” (MENEZES CORDEIRO, 2015, p. 1234).

O microssistema de defesa do consumidor protege a confiança, na qualidade de expectativas legítimas, do consumidor no mercado de consumo (MIRAGEM 2017). Assim, se o fornecedor teve atuação (no sentido de comportamento ou emissão de informações) a despertar a confiança do consumidor de forma legítima, vinculando-o a uma ação futura (seja positiva ou negativa, isto é, de outra conduta ou manutenção de determinado estado de fato), então esta confiança terá o condão de produzir efeitos jurídicos em seu sentido, a partir da consideração de que constitui a base do comportamento humano (LARENZ, 1959).

A proteção da confiança remete aos tempos pós-modernos, em que há uma valorização especial àquilo que é, cada vez mais, visual (BENJAMIN; MARQUES; BESSA, 2014). Foi esta que fez com que a "vontade" do contrato fosse, em importância, transferida para a "declaração"; e, hoje, transfere-se para ela própria: a confiança, a construir teorias como a da aparência no mercado de consumo, por exemplo. Em síntese, o principio da confiança no microssistema de defesa do consumidor resultará na preservação da posição nela 


\section{O EQUILÍBRIO CONTRATUAL NO DIREITO PRIVADO PÓS-MODERNO: \\ A (RE)SIGNIFICAÇÃO DA JUSTIÇA DO CONTRATO NO MICROSSISTEMA DE DEFESA DO \\ CONSUMIDOR}

alicerçada ou nos efeitos indenizatórios da responsabilidade civil, se a ofensa às expectativas legítimas dos consumidores resultarem danosas (MENEZES CORDEIRO, 2015).

O princípio da boa-fé, em que pese a caminhar ao lado da confiança em todos os tempos, não tem o seu conteúdo a ela vinculado. Este, remete não a expectativas legítimas dos consumidores, mas cuida, sim, dos comportamentos dos agentes no mercado de consumo, estabelecendo um modelo, um standard de atuação (MENEZES CORDEIRO, 2015). Para Larenz (1959, p. 141), a boa-fé objetiva significa que "cada uno debe guardar 'fidelidad' a la palabra dada y no defraudar la confianza o abusar de ela". Nesse sentido, a boa-fé faz criar, nas relações contratuais, deveres anexos, laterais, de conduta ou instrumentais às partes, independentes dos principais, exigindo que haja, no mercado de consumo, um ambiente cooperativo, de lealdade, de consideração ao outro (COUTO E SILVA, 2014).

A boa-fé, como princípio, tem o condão de aniquilar os interesses tão-somente egoísticos das partes, como se estivessem em pólos contratuais adversos, para que, então, tenham informadas, as suas ações, pelo respeito aos interesses alheios, tornando-os solidários (MIRAGEM, 2017). É esse o ambiente que a matriz principiológica do CDC almeja concretizar. Este é o núcleo do justo contratual. A boa-fé, assim, dirige-se, em especial, ao julgador, estimulando-o a responder aos novos fatos que lhes são apresentados, a fim de que realize um controle corretivo dos desequilíbrios encontrados nas relações contratuais de consumo (COUTO E SILVA, 2014).

Por tais razões, o equilíbrio contratual do contrato de consumo, construído sobre os pilares da confiança e da boa-fé, aproxima-se do conteúdo nuclear da justiça contratual das relações de consumo, que só será legítima se atingir a igualdade substancial. Por todo o exposto, a justiça do contrato, no microssistema de defesa do consumidor, é objetivo que deve ser alcançado nas três fases da relação contratual - a pré, a executória e a pós -, apenas podendo-se dizer que foi alcançada se observada a partir de uma visão global do contrato. Justo haverá de ser a relação contratual de consumo que respeite não só a prestação principal e acessória, de conteúdo econômico, mas, também, os deveres de conduta dos contraentes, em especial o informacional, como dito antes, assegurando um equilíbrio mínimo entre as partes, os seus direitos e os seus deveres contratuais, para que concretamente o consumidor tenha a satisfação de suas expectativas e de seus interesses com a consecução do negócio (MENEZES CORDEIRO, 2015). 


\section{CONSIDERAÇÕES FINAIS}

Após ter-se alcançado o fim do desenvolvimento deste estudo, partiremos, por fim, às considerações finais, a partir das conclusões obtidas no decorrer da pesquisa:

1. O microssistema de defesa do consumidor alterou, profundamente, o significado da justiça contratual na teoria dos contratos. Se, para a teoria contratual clássica, oriunda do direito privado moderno, a justiça do contrato poderia ser alcançada a partir da realização das vontades das partes refletidas pelo instrumento contratual, quando celebrado, este, por indivíduos - abstratamente considerados - livres e iguais (perante a lei), verdade é que, no direito do consumidor, tal premissa tornou-se inadequada. A um, porque o contrato é, na grande maioria das vezes, contratos de massa, unilateralmente edificados por um dos sujeitos contratuais - o agente econômico fornecedor. E, a dois, porque, na relação de consumo, formada, de um lado, por um fornecedor, e, de outro, por um consumidor, estes não são, formal, nem materialmente, iguais. Logo, a premissa da teoria clássica, para a consolidação da noção de justiça contratual torna-se, a priori, inadequada, porque não se ajusta à realidade do mercado de consumo, nem de sua tutela jurídica.

2. Para além disso, o significado da justiça contratual alterou-se não só pela sua inadequação, mas, sim, por atingir o conteúdo da relação contratual, diferentemente do que ocorreu outrora - na teoria clássica dos contratos, não havia uma análise sobre a justiça contratual a partir do conteúdo do contrato e da realidade das partes contratantes - bastava considerar abstratamente as suas vontades, liberdades e igualdade. No microssistema de defesa do consumidor, diversamente, importa alcançar um real equilíbrio contratual entre as partes, sob pena de ser considerado injusto. Observa-se, aqui, que até então não se havia falado sobre equilíbrio.

3. Parte-se da consideração de que o consumidor é, presumivelmente, vulnerável em face dos fornecedores do mercado de consumo. Isso se dá por razões que dependem da análise de casos concretos: quase sempre, em razão da superioridade econômica do fornecedor; também técnica e informacional. Por ser o fornecedor quem redige o contrato de consumo, é ele, também, quem distribui os direitos e os deveres de cada parte, por vezes aumentando os seus direitos e reduzindo os seus deveres. É desta distribuição que pode nascer o desequilíbrio contratual. A justiça do contrato apenas há de ser alcançada quando o desequilíbrio do caso concreto na relação contratual não onere excessivamente o consumidor. 


\section{O EQUILÍBRIO CONTRATUAL NO DIREITO PRIVADO PÓS-MODERNO: A (RE)SIGNIFICAÇÃO DA JUSTIÇA DO CONTRATO NO MICROSSISTEMA DE DEFESA DO

4. Se - para que se alcance a justiça do contrato - há de se conquistar um equilíbrio do conteúdo da relação contratual entre o fornecedor e o consumidor, para que ambos extraiam vantagens do negócio firmado, em que pese as suas reais desigualdades, o microssistema de defesa do consumidor não retira, mas reduz, substancialmente em relação à teoria clássica, a liberdade contratual entre as partes - esta liberdade, sabe-se, não é possível nas relações de consumo, a começar porque quem redige o conteúdo do contrato é apenas uma das partes, não havendo, à outra, o poder de modificar as cláusulas. A liberdade, não mais um dogma, aqui, torna-se um dos pilares do contrato, porém divide espaço com valores, outros, irradiados pela matriz principiológica do microssistema de defesa do consumidor, os quais são, fundamentalmente, o da confiança e o da boa-fé.

5. O microssistema de defesa do consumidor protege as legítimas expectativas do consumidor em suas relações contratuais com o fornecedor. Essa premissa é edificada à luz do princípio da confiança. Se confia aquele que acredita, firmemente, em determinada realidade e que se movimenta em determinado sentido a partir e em razão dela, o Direito assegura seja, essa projeção - se legítima - realizada conforme o confiado. Só assim há um equilíbrio na relação contratual, evitando a frustração e a injustiça do respectivo conteúdo.

6. A boa-fé objetiva, a qual não se confunde com a confiança, mas ao lado dela caminha, pode ser compreendida, na proteção contratual do consumidor, a partir de suas funções: estabelece um padrão de comportamentos no mercado de consumo, evitando (portanto, prevenindo) um desequilíbrio deste pelos fornecedores no sentido de tornar-se prejudicial excessivamente aos seus consumidores. Pela boa-fé, os fornecedores (mas, também, os consumidores) precisam realizar os seus contratos em colaboração intersubjetiva, com zelo, sem lesar o outro ou o patrimônio do outro. A boa-fé objetiva serve, também, ao magistrado, para interpretar o contrato não apenas com base no seu conteúdo explícito, elaborado pelo fornecedor, mas, também, com base em uma visão global de seu conteúdo e da realidade das partes e de suas forças naquela relação, equilibrando os seus direitos e os seus deveres de modo a não permitir que a um só deles torne-se desvantajoso ou excessivamente oneroso adimpli-lo. É a boa-fé que, sobremaneira, delimita o conteúdo da liberdade contratual, através da atividade do magistrado.

7. Pode-se concluir, assim, em síntese, que a justiça contratual no microssistema de defesa do consumidor é alcançada quando há um equilíbrio não só entre os direitos e os deveres contratuais entre os fornecedores e os consumidores, mas, também, quando - no interior de 
cada relação, irradia os princípios da liberdade contratual, da confiança e da boa-fé - este último a delimitar o espaço dos dois primeiros, visando alcançar as legítimas expectativas do consumidor e assegurando a realização da liberdade das partes em celebrar o contrato unilateralmente estipulado pelo fornecedor (única forma que tem de organizar a sua atividade de forma previsível e a alcançar número indeterminado de clientes), sem, todavia, onerá-los excessivamente.

\section{REFERÊNCIAS}

ALMEIDA COSTA, Mário Júlio de. Direito das obrigações. 12 ed. Coimbra: Almedina, 2011.

ANTUNES VARELA, João de Matos. Das Obrigações em geral. Vol. I. 9 ed. Coimbra: Livraria Almedina, 1998.

BENJAMIN, Antonio Herman V.; MARQUES, Claudia Lima; BESSA, Leonardo Roscoe. Manual de direito do consumidor. 6 ed. São Paulo: Revista dos Tribunais, 2014.

BOBBIO, Norberto. A Era dos Direitos. Tradução de Carlos Nelson Coutinho. 6 tiragem. Rio de Janeiro: Elsevier, 2004.

CARNEIRO DA FRADA, Manuel António. Teoria da confiança e responsabilidade civil. Lisboa: Almedina, 2004.

COMPARATO, Fábio Konder. A afirmação histórica dos direitos humanos. 10 ed. São Paulo: Saraiva, 2015.

COUTO E SILVA, Clovis V. do. A Obrigação como processo. Rio de Janeiro: Editora FGV, 2006.

COUTO E SILVA, Clóvis do. A teoria da base do negócio jurídico no Direito brasileiro. In: FRADERA, Vera Maria Jacob de (Org.). O Direito Privado brasileiro na visão de Clóvis do Couto e Silva. 2 ed. Porto Alegre: Livraria do Advogado, 2014, p. 87-94.

COUTO E SILVA, Clóvis do. O Direito Civil brasileiro em perspectiva histórica e visão de futuro. In: FRADERA, Vera Maria Jacob de (Org.). O Direito Privado brasileiro na visão de Clóvis do Couto e Silva. 2 ed. Porto Alegre: Livraria do Advogado, 2014, p. 11-30.

COUTO E SILVA, Clóvis do. O princípio da boa-fé no Direito brasileiro e português. In: FRADERA, Vera Maria Jacob de (Org.). O Direito Privado brasileiro na visão de Clóvis do Couto e Silva. 2 ed. Porto Alegre: Livraria do Advogado, 2014, p. 31-56.

GOMES, Orlando. Transformações gerais do direito das obrigações. São Paulo: Revista dos Tribunais, 1967. 


\section{O EQUILÍBRIO CONTRATUAL NO DIREITO PRIVADO PÓS-MODERNO: A (RE)SIGNIFICAÇÃO DA JUSTIÇA DO CONTRATO NO MICROSSISTEMA DE DEFESA DO

LARENZ, Karl. Base del negocio jurídico y cumplimiento de los contratos. Trad. de Carlos Fernández Rodríguez. Granada: Editorial Comares, S. L., 2002.

LARENZ, Karl. Derecho de obligaciones. Tomo I. Versión española y notas de Jaime Santos Briz. Madrid: Revista de Derecho Privado, 1959.

MARQUES, Claudia Lima. Contratos no Código de Defesa do Consumidor: o novo regime das relações contratuais. 8 ed. São Paulo: Revista dos Tribunais, 2016.

MARQUES, Claudia Lima; MIRAGEM, Bruno. O novo direito privado e a proteção dos vulneráveis. São Paulo: Revista dos Tribunais, 2012.

MENEZES CORDEIRO, António. Direito das Obrigações. Vol. 1. Lisboa: Edição da Assóciação Académica da Faculdade de Direito de Lisboa, 1994.

MENEZES CORDEIRO, António. Da boa fé no direito civil. 6 reeimp. Coimbra: Almedina, 2015.

MIRAGEM, Bruno. Curso de direito do consumidor. 6 ed. São Paulo: Revista dos Tribunais, 2016.

MIRAGEM, Bruno. Direito Civil: Direito das Obrigações. São Paulo: Saraiva, 2017.

NEGREIROS, Teresa. Teoria do Contrato: novos paradigmas. 2 ed. Rio de Janeiro: Renovar, 2006.

PEREIRA, Caio Mário da Silva. Lesão nos contratos. 6 ed. Rio de Janeiro: Forense, 1994.

REALE, Miguel. Nova fase do direito moderno. São Paulo: Saraiva, 1990.

RIPERT, Georges. A regra moral nas obrigações civis. São Paulo: Bookseller, 2000.

ROPPO, Enzo. O contrato. Trad. de Ana Coimbra e M. Januário C. Gomes. Coimbra: Almedina, 2009. 